\title{
Administration of a plasmid that expresses SDF-1 $\alpha$ affects the oncogenic potential of mouse bcr-abl-transformed cells
}

\author{
VINCENT LUCANSKY* ${ }^{*}$ MONIKA KRMENCIKOVA-FLIEGL ${ }^{*}$, LIBOR STANEK and VLADIMIR VONKA \\ Department of Experimental Virology, Institute of Hematology and Blood Transfusion, CZ-128 20 Prague 2, Czech Republic
}

Received October 18, 2013; Accepted December 6, 2013

DOI: $10.3892 / \mathrm{mmr} .2014 .2425$

\begin{abstract}
Stromal-derived factor $1 \alpha$ (SDF-1 $\alpha$, also known as CXCL12) is a chemokine that exerts its effects through the $\mathrm{G}$-protein coupled receptors, $\mathrm{C}-\mathrm{X}-\mathrm{C}$ chemokine receptor type 4 (CXCR4) and 7 (CXCR7). There is marked evidence that the SDF-1/CXCR4 axis is involved in the pathogenesis of leukemia and therapies that target this axis are under development. The present study aimed to increase the efficacy of a DNA-based bcr-abl vaccine by simultaneously immunizing mice with a plasmid carrying the whole SDF-1 $\alpha$ gene. Bcr-abl-transformed 12B1 cells were used to challenge the mice. These cells have the oncogenic potential to induce both leukemia following intravenous inoculation and lymphoma-type solid tumors after subcutaneous inoculation. Administering an SDF-1 carrying plasmid together with the bcr-abl vaccine resulted in increased survival following a challenge with subcutaneously administered 12B1 cells, although the difference was not statistically significant. However, there was a difference when the animals that developed subcutaneous tumors were only taken into consideration. In doubly-treated mice, significantly more mice failed to develop solid tumors than mice that had only received the bcr-abl vaccine. By contrast, the occurrence of fatal leukemia was significantly higher in the mice that were treated with the SDF-1 plasmid, regardless of whether they were immunized with the bcr-abl-vaccine. No humoral or cellular immune responses against SDF-1 were detected in the treated mice, which suggested that the changes in oncogenic potential of $12 \mathrm{~B} 1$ cells were due to the activity of SDF-1 itself.
\end{abstract}

Correspondence to: Professor Vladimir Vonka, Department of Experimental Virology, Institute of Hematology and Blood Transfusion, U Nemocnice 1, CZ-128 20 Prague 2, Czech Republic E-mail:vonka@uhkt.cz

*Contributed equally

Key words: stromal-derived factor $1 \alpha$, bcr-abl, mice, solid tumors, leukemia

\section{Introduction}

Stromal-derived factor-1 $\alpha$ (SDF-1 $\alpha$ ), also known as CXCL12, is one of $\sim 50$ soluble peptides that have been characterized as chemokines. SDF- $1 \alpha$ is expressed in a wide range of malignant tissues as well as in various normal tissues. Its physiological expression has been documented in a number of organs, including heart, brain, kidney, adrenal glands, liver, lung, skeletal muscles, lymphoid organs and bone marrow $(1,2)$. In these tissues, vascular endothelial cells, stromal fibroblasts and osteoblasts are major SDF-l $\alpha$ producers (2). SDF-l $\alpha$ secretion increases during tissue damage, limb ischemia, toxic liver damage, excessive bleeding, total body irradiation and damage associated with chemotherapy.

SDF-l $\alpha$ was originally described as a pre-B cell growth factor (3). However, a number of different functions for this chemokine have subsequently been determined. Under normal conditions, SDF-1 participates in regulating hematopoiesis and modulating the immune system via signaling through C-X-C chemokine receptor 4 (CXCR4), which mediate chemotaxis and have an important role in cell-homing responses $(4,5)$. It is also a modulator of cell growth and survival (6). CXCR4 was originally considered to be the only receptor for this chemokine. However, it has been identified that SDF-1 $\alpha$ also reacts with the CXCR7 receptor (7). A considerable amount of evidence on CXCR4 and CXCR7 receptors has accumulated in recent years (8).

SDF- $1 \alpha$ affects the chemoattraction of $\mathrm{CXCR} 4^{+}$cells, which is necessary for tissue/organ regeneration $(9,10)$. For oncological malignancies, the SDF-1 $\alpha /$ CXCR 4 axis promotes tumor progression by several different mechanisms. The most important of these appear to be: (i) directly supporting the growth of neoplastic cells; (ii) promoting metastatic spread to organs that highly express SDF-1 $\alpha$; (iii) supporting tumor angiogenesis by attracting endothelial cells to the tumor microenvironment and reducing extracellular angiostatin levels by downregulating phosphoglycerate kinase (PGK) $(2,4,9,11-13)$. It has also been demonstrated that SDF-1 $\alpha$ promotes cytotoxic T-cell apoptosis (14).

Stromal elements are attractive therapeutic targets due to their roles in tumor biology (15) and a number of studies that target the SDF- $1 \alpha /$ CXCR4 axis are under way at present. It has already been demonstrated that CXCR4 antagonists may have anti-tumor activities in patients with various malignancies (16). This treatment appears to affect both the capability 
to disseminate tumor cells and the sensitivity of a tumor to immunotherapy (17).

In the present study, bcr-abl-transformed mouse 12B1 cells were utilized and the effects of SDF- $1 \alpha$ administration on the efficacy of a DNA vaccine carrying a complete bcr-abl fusion gene was investigated. The original hypothesis proposed that repeated intracutaneous administration of a plasmid carrying the SDF- $1 \alpha$ gene may induce immune reactions against this chemokine and result in enhancing the immunogenicity of the bcr-abl-directed vaccine. The results indicated that this did not occur. However, administering this chemokine did result in a change in the oncogenic potential of the bcr-abl-transformed mouse $12 \mathrm{~B} 1$ cells.

\section{Materials and methods}

Cells. The 12B1 cells derived from BALB/c mouse bone marrow cells transfected with a human bcr-abl fusion gene and expressing the BCR-ABL fusion protein (18) were consistent with those used in previous studies (19-21). These cells are of early B-cell lineage (Krmencikova-Fliegl; manuscript in preparation) and induce acute leukemia-like disease following intravenous inoculation, but form solid tumors when administered subcutaneously. To monitor the activity of a newly constructed plasmid (see below), 293T cells were used. These were cultured as previously described (22). K562 and HeLa cells were used as positive controls for western blotting. The HeLa cell line was grown in Dulbecco's Modified Eagle Medium (DMEM; PAA Laboratories, Pasching, Austria) supplemented with $10 \%$ fetal bovine serum (PAA Laboratories) and antibiotics. K562 cells were cultured as described previously (23).

Mice. Female BALB/c mice aged 5-6 weeks were obtained from Charles River Laboratories (Sulzfeld, Germany). All of the experimental animal procedures were performed in accordance with the validated regulations of the Czech Republic. The study was approved by the Ethics Committee of the First Medical Faculty, Charles University (Prague, Czech Republic).

Plasmids. The construction of a mammalian expression plasmid, pBSC, used as a negative control and a pBSC/bcr-abl plasmid carrying the whole bcr-abl gene, was conducted as described previously $(19,24)$. A plasmid designated pBSC/SDF1 $\alpha$ was prepared using a pUC57/SDF-1 $\alpha$ plasmid (GeneScript, Piscataway, NJ, USA) carrying the whole SDF1 $\alpha$ gene flanked with a Flag sequence. A fragment encoding for SDF-1 $\alpha$ and Flag was obtained by cleavage with EcoRI and Bgl III (New England Biolabs, Inc., Ipswich, MA, USA) and subsequently inserted into a pBSC plasmid downstream of the immediately early human cytomegalovirus promotor using the same restriction sites. The inserted gene was re-sequenced with satisfactory results.

Western blotting. To verify the functionality of our new construct, 293T cells were transfected either with the pBSC/SDF-1 $\alpha$ plasmid or with an empty pBSC used as a control. Following 2 days, the cells were harvested and lysed with Kaufman buffer. The cell lysates were examined by western blotting as described previously (23). A mouse monoclonal antibody against Flag (Amersham Biosciences,
Little Chalfont, UK) was used as the primary antibody and a peroxidase labeled anti-mouse antibody (GE Healthcare, Little Chalfont, UK) was used as the secondary antibody.

To test for the presence of SDF-1 $\alpha$ in the lysates of 12B1 cells, a goat anti-SDF/PBSF antibody (Sigma-Aldrich, St. Louis, MO, USA), a rabbit anti-SDF-1 antibody (Abcam, Cambridge, UK), horseradish-peroxidase-labeled donkey anti-goat IgG antibody (Santa Cruz Biotechnology, Inc., Santa Cruz, CA, USA) and peroxidase-labeled anti-rabbit IgG antibody (Amersham Biosciences), respectively, were used. The $293 \mathrm{~T}$ cells transfected with pBSC/SDF-1 $\alpha$ plasmids and with empty pBSC plasmids were used as positive and negative controls, respectively. To detect hypoxia-inducible factor- $1 \alpha$ (HIF-1 $\alpha$ ) a mouse monoclonal anti-HIF-1 $\alpha$ antibody (Sigma, St. Louis, MO, USA) and peroxidase labeled anti-mouse antibody (GE Healthcare, Little Chalfont, UK) were used. An anti-CXCR4 rabbit polyclonal antibody (Abcam) and horseradish-peroxidase-labeled anti-rabbit IgG antibody (GE Healthcare) were used to detect the CXCR4 protein expression levels in lysates of 12B1 cells and in lysates from cultures derived from 12B1 cell-induced solid tumors.

To prepare cytosolic and nuclear extracts of 12B1 cells, a total of $10^{7}$ cells were washed two times in PBS. A mixture was prepared consisting of $5 \mathrm{ml}$ of buffer A (10 mM HEPES, $\mathrm{pH} 7.9,10 \mathrm{mM} \mathrm{KCl}$ and $0.1 \mathrm{mM}$ EDTA), $5 \mu \mathrm{l}$ of a protease inhibitor cocktail (Sigma-Aldrich) and $200 \mu \mathrm{l}$ of $10 \%$ IGEPAL (Sigma-Aldrich). This mixture was added directly to the cell pellets. Following a $10 \mathrm{~min}$ incubation at room temperature, the mixture was repeatedly pipetted up and down with a P1000 (Nichyrio America, Inc., Maryland Heights, MO, USA) to disrupt the cell clumps and then transferred to pre-chilled microcentrifuge tubes. Following centrifugation $(13,000 \mathrm{x} g$ at $4^{\circ} \mathrm{C}$ for $3 \mathrm{~min}$ ), the supernatant (cytosolic fraction) was retrieved and stored at $-70^{\circ} \mathrm{C}$. The remaining pellet was resuspended in $150 \mu \mathrm{l}$ of buffer B (20 mM HEPES, pH 7.9, $0.4 \mathrm{M}$ $\mathrm{NaCl}, 1 \mathrm{mM}$ EDTA and 10\% glycerol) supplemented with $1 \mu \mathrm{l}$ of a protease inhibitor cocktail. The mixture was shaken vigorously at $4^{\circ} \mathrm{C}$ for $2 \mathrm{~h}$. The nuclear extract was centrifuged $\left(13,000 \mathrm{x} \mathrm{g}\right.$ at $4^{\circ} \mathrm{C}$ for $\left.5 \mathrm{~min}\right)$ and stored at $-70^{\circ} \mathrm{C}$. A Bradford assay was used to determine the protein concentrations.

To detect tubulin, a mouse monoclonal anti- $\beta$ tubulin antibody (Sigma) and peroxidase labeled anti-mouse antibody (GE Healthcare) were used.

Immunization procedure. The DNA cartridges for a gene gun were prepared according to the manufacturer's instructions (Hélios Gene Gun System; Bio-Rad, Hercules, CA, USA). Each cartridge contained $1 \mu \mathrm{g}$ of DNA on gold particles, $1 \mu \mathrm{m}$ in diameter. DNA was administered intradermally into a shaven abdominal area. When using pBSC and pBSC/SDF- $1 \alpha$ plasmids, three doses were administered at two week intervals. The plasmid pBSC/bcr-abl was administered only twice, simultaneously with the second and third doses of the other plasmids. This suboptimal immunization scheme (two doses of the $\mathrm{pBSC} / \mathrm{bcr}-\mathrm{abl}$ vaccine induces only incomplete protection) was selected to allow for the manifestation of possible SDF-1 $\alpha$ effects.

Two weeks following the last dose, the mice were challenged with $5 \times 10^{3} 12 \mathrm{~B} 1$ cells (i.e., $\sim 10 \mathrm{TID}_{50}$ ). Each experiment included four groups of mice (6 mice/group): (i) mice that 
Table I. Peptide sequences used for in-house ELISAs. These peptides covered the whole amino-acid sequence of the SDF-1 protein and overlapped by 10 amino acids.

Peptide designation

Peptide sequence

Peptide length

SDF- $1 \alpha 1 / 3$

SDF- $1 \alpha 2 / 3$

SDF- $1 \alpha 3 / 3$

MDAKVVAVLALVLAALCISDGKPVSLSYRCPCRFFE
SYRCPCRFFESHIARANVKHLKILNTPNCALQIVARL
NCALQIVARLKNNNRQVCIDPKLKWIQEYLEKALNK

SDF- $1 \alpha$, stromal-derived factor $1 \alpha$; aa, amino acids.

received the empty pBSC plasmid (control group); (ii) mice that received only the $\mathrm{pBSC} / \mathrm{SDF}-1 \alpha$ plasmid; (iii) mice that received only the $\mathrm{pBSC} / \mathrm{bcr}-\mathrm{abl}$ vaccine; and (iv) mice that were inoculated with both the $\mathrm{pBSC} / \mathrm{bcr}-\mathrm{abl}$ and $\mathrm{pBSC} / \mathrm{SDF}-1 \alpha$ plasmids. These experiments were repeated four times. The mice were followed for 50 days following these challenges. When the tumors reached a size of $400 \mathrm{~mm}^{2}$, the mice were humanely sacrificed.

ELISA. To examine the possible development of SDF-1 $\alpha$ specific antibodies, the plasma samples of the treated and control mice were investigated using an in-house ELISA. The sequences of the peptides used are presented in Table I. These were purchased from Peptide 2.0, Inc. (Chantilly, VA, USA). The peptides used covered the whole amino acid sequence of the SDF-1 protein and mutually overlapped by $\sim 10$ amino acids. This was performed to avoid the possible loss of any important epitopes and was conducted as described previously (25).

To examine for the presence of SDF-1 $\alpha$ in the media of the 12B1 cell cultures, a mouse CXCL12/SDF-1 $\alpha$ ELISA kit (Cell Sciences, Inc., Canton, MA, USA) was used following the manufacturer's instructions.

ELISPOT assay. To examine for the possible development of cell-mediated immune responses against SDF-1 $\alpha$, an ELISPOT assay was used as described previously (26). Lymphocytes $\left(8 \times 10^{5}\right)$ from the mice inoculated with either pBSC or $\mathrm{pBSC} / \mathrm{SDF}-1 \alpha$ plasmids were incubated with several concentrations $(0.1 \mu \mathrm{g}, 1 \mu \mathrm{g}$ and $10 \mu \mathrm{g})$ of KVVAVLAL peptides. This sequence located at the N-terminus of the SDF-1 $\alpha$ protein had a high T-epitope score using both 'Syfpeithi' and 'Rankpep' prediction software. Lymphocytes that produced interferon- $\gamma$ (INF- $\gamma$ ) were detected with an ImmunoSpot S5 UV Lite Analyzer (Cellular Technology Limited, Shaker Heights, OH, USA).

Statistical analysis. Survival analysis for the experimental groups used log-rank tests. Statistical analysis was performed using Prism software version 5.0 (Graph-Pad Software, La Jolla, CA, USA). $\mathrm{P}<0.05$ was considered to indicate a statistically significant difference.

\section{Results}

Functionality of the $p B S C / S D F-1 \alpha$ plasmid. Firstly, the functionality of the newly constructed $\mathrm{pBSC} / \mathrm{SDF}-1 \alpha$ plasmid

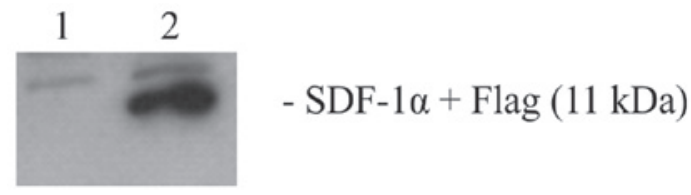

Figure 1. SDF-1 $\alpha$ in lysates of transfected $293 \mathrm{~T}$ cells. Lane 1, comparison of lysates from $293 \mathrm{~T}$ cells transfected with empty pBSC plasmid; lane 2, 293T cells transfected with pBSC/SDF-1 $\alpha$ plasmid. Monoclonal mouse anti-Flag antibody and labeled anti-mouse antibody were used. SDF-1 $\alpha$, stromalderived factor $1 \alpha$.

was examined. The western blotting results using lysates of transfected and mock-transfected 293T cells are revealed in Fig. 1. This demonstrated that SDF-1 $\alpha$ was present in the lysates of pBSC/SDF-1 $\alpha$-transfected cells but not in the lysates of control pBSC-transfected cells.

Absence of SDF-1 and presence of CXCR4 and HIF-1 $\alpha$ in $12 \mathrm{Bl}$ cells. The culture media and the cell lysates of 12B1 cells were examined for the presence of SDF-1 $\alpha$, by ELISA and western blotting, respectively. SDF-1 $\alpha$ was not detected in either of these preparations using two different antibody systems (results not shown). By contrast, the lysates of 12B1 cells and the lysates obtained from the subcutaneous tumors, and from cultures derived from them, contained substantial amounts of CXCR4 (Fig. 2A). CXCR4 was detected both in the cytosolic and nuclear fractions of the 12B1 cells (Fig. 2B). HIF- $1 \alpha$ was also detected in the lysates of the 12B1 cells (Fig. 2C).

Survival of SDF-1 treated and untreated mice following challenge with $12 \mathrm{Bl}$ cells. A total of four repeat experiments were performed with each, including 24 mice divided into four groups as described in Materials and methods. Although the immunization effects differed somewhat from experiment to experiment, for each experiment, more mice survived (2, 1, 1 and 3 , respectively) that were treated with both the $\mathrm{pBSC} / \mathrm{bcr}-\mathrm{abl}$ and $\mathrm{pBSC}-\mathrm{SDF}-1 \alpha$ plasmids than those that only received the $\mathrm{pBSC} / \mathrm{bcr}-\mathrm{abl}$ plasmid. A summary of these four experiments is illustrated in Fig. 3.

Close to all of the control mice (23/24) that were treated with the empty plasmid were dead on day 24 following challenge; mice were humanly sacrificed either due to a large tumor size (22/23) or because they were dying of leukemia (1/23). For mice that only received the pBSC-SDF- $1 \alpha$ plasmid, several survived (3/24). Furthermore, a number of these mice achieved a prolonged survival. 


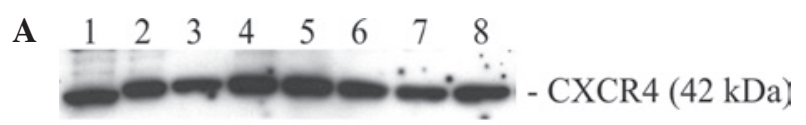

B

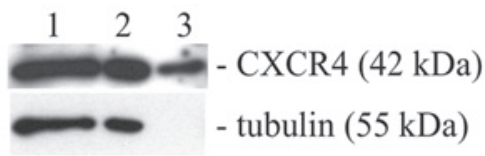

C

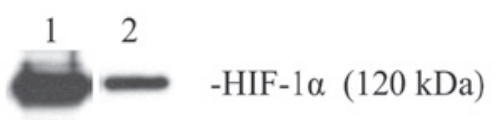

Figure 2. (A) CXCR4 in lysates. Lane 1, HeLa cells; lane 2, 12B1 cells. CXCR4 in tumors induced by 12B1 cells and cell lines derived from them. Lanes $3,5,7$, the samples obtained from tumors immediately following necropsy; lanes $4,6,8$, the samples obtained from cell cultures derived from tumors. (B) CXCR4 protein in 12B1 cells. Lysates of 12B1 cells: Lane 1, whole cells; lane 2, cytosolic fraction; lane 3 nuclear fraction. Tubulin was used as a control to assess the purity of nuclear fractions. (C) HIF-1 $\alpha$ in lysates; lane 1, human K562 cells; lane 2, 12B1 cells. CXCR4, C-X-C chemokine receptor type 4 ; HIF- $1 \alpha$, hypoxia-inducible factor $1 \alpha$.

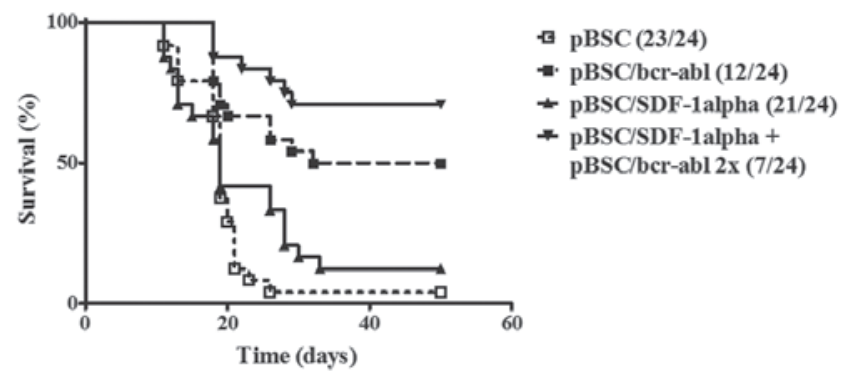

Figure 3. Survival of mice inoculated with empty pBSC (control), $\mathrm{pBSC} / \mathrm{SDF}-1 \alpha, \mathrm{pBSC} / \mathrm{bcr}-\mathrm{abl}$, and both $\mathrm{pBSC} / \mathrm{SDF}-1 \alpha$ and $\mathrm{pBSC} / \mathrm{bcr}-\mathrm{abl}$ plasmids, which were then challenged with $12 \mathrm{~B} 1$ cells. The data represent a summary of four repeated experiments. The difference in survival between the mice that received the immunizing $\mathrm{pBSC} / \mathrm{bcr}$-abl plasmid and mice that were not inoculated with it was highly significant $(\mathrm{P}<0.001)$. Other differences in survival were not significant $(\mathrm{P}>0.05)$. SDF-1 $\alpha$, stromal-derived factor-1 $\alpha$.

As expected, more mice survived following receiving the specific vaccine. Of those immunized with the $\mathrm{pBSC} / \mathrm{bcr}-\mathrm{abl}$ vaccine alone, 12/24 (50\%) survived. The number of survivors in the group that received both the pBSC/bcr-abl and pBSC/SDF1 $\alpha$ plasmids was higher. A total of 17/24 (70.8\%) mice survived, which suggested that SDF-1 $\alpha$ plasmid administration had a protective effect. The difference in survival between pBSC/bcr-abl immunized and non-immunized mice was highly significant $(\mathrm{P}<0.001)$. However, the differences in survival between the SDF-1 $\alpha$ treated and untreated mice noted above were not statistically significant.

However, when the mice that developed solid tumors were only taken into consideration, the results were markedly different. As demonstrated in Fig. 4A, the occurrence of solid tumors was considerably lower in mice that were treated with both the pBSC/bcr-abl vaccine and the pBCS/SDF-1 $\alpha$ plasmid than in those that were immunized only with the pBSC/bcr-abl vaccine. This difference was statistically significant $(\mathrm{P}=0.0115)$. There were also differences in solid tumor formation between the $\mathrm{pBSC} / \mathrm{bcr}-\mathrm{abl}$ non-immunized mice that were either treated or untreated with the SDF-1
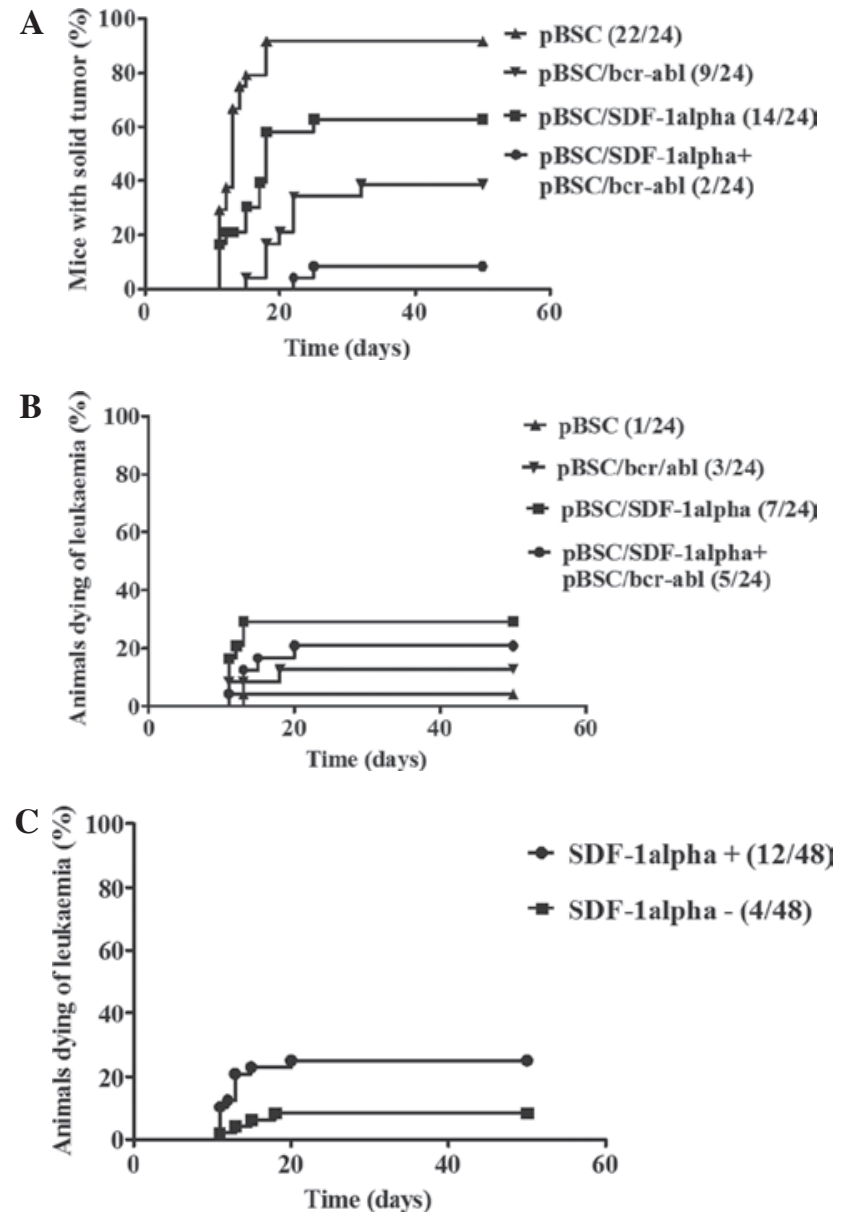

Figure 4. Development of either solid tumors or fatal leukemia in mice inoculated with empty pBSC plasmid (control), pBSC/SDF-1 $\alpha$ plasmid, pBSC/bcr-abl plasmid, or both pBSC/SDF-1 $\alpha$ and pBSC/bcr-abl plasmids, which were then challenged with 12B1 cells. (A) Solid tumor development in all of the mouse groups. The occurrence of solid tumors was higher and the tumors appeared earlier in mice that did not receive the $\mathrm{pBSC} / \mathrm{SDF}-1 \alpha$ plasmid, as compared with the mice that were administered this plasmid. The difference between $\mathrm{pBSC} / \mathrm{SDF}-1 \alpha$ treated and untreated mice was statistically significant for both bcr-abl immunized and non-immunized mice ( $\mathrm{P}=0.0115$ and $\mathrm{P}=0.0023$, respectively). (B) Fatal leukemia development in all of the mouse groups. Although the difference between bcr-abl immunized mice was not statistically significant $(\mathrm{P}=0.0517)$, the development of fatal leukemia in the $\mathrm{pBSC} / \mathrm{bcr}-\mathrm{abl}$ non-immunized $\mathrm{pBSC} / \mathrm{SDF}-1 \alpha$ treated and untreated mice was statistically significantly different $(\mathrm{P}=0.0191)$. (C) Fatal leukemia development in all of the mouse groups regardless of immunization with the $\mathrm{pBSC} / \mathrm{bcr}-\mathrm{abl}$ plasmid. The difference between $\mathrm{pBSC} / \mathrm{SDF}-1 \alpha$ treated and untreated mice was statistically significant $(\mathrm{P}=0.0265)$. SDF-1 $\alpha$, stromal-derived factor- $1 \alpha$.

plasmid. The occurrence of solid tumors was higher and the tumors appeared earlier in mice that did not receive the $\mathrm{pBSC} / \mathrm{SDF}-1 \alpha$ plasmid than in mice to which this plasmid was administered. This difference was also statistically significant $(\mathrm{P}=0.0023)$. The occurrence of fatal leukemia is revealed in Fig. 4B. Although the difference within bcr-abl immunized mice was not statistically significant $(\mathrm{P}=0.0517)$, the development of fatal leukemia in $\mathrm{pBSC} / \mathrm{bcr}-\mathrm{abl}$ non-immunized, $\mathrm{pBSC} / \mathrm{SDF}-1 \alpha$ treated and untreated mice was significantly different $(\mathrm{P}=0.0191)$. As is also revealed in Fig. 4C, when comparing all of the mice (i.e., including those immunized with the $\mathrm{pBSC} / \mathrm{bcr}-\mathrm{abl}$ vaccine) that were either treated or not treated with the $\mathrm{pBSC} / \mathrm{SDF}-1 \alpha$ plasmid, 
the development of leukemia was statistically significantly different $(\mathrm{P}=0.0265)$.

Possible immune responses to SDF-1. To determine whether the observed differences noted above were associated with the development of immune responses against SDF- $1 \alpha$ induced by the intradermally administered $\mathrm{pBSC} / \mathrm{SDF}-1 \alpha$ plasmid, we assayed for the presence of both specific antibodies using ELISA with SDF-1 $\alpha$-derived peptides and cell mediated immunity using an ELISPOT assay with an SDF-1 $\alpha$-derived peptide carrying a putative $\mathrm{T}$ epitope, as predicted by two different programs. Both of these tests were negative (results not shown).

\section{Discussion}

The aim of the present study was to induce an immune response against SDF- $1 \alpha$ and to monitor its effects on the efficacy of the pBSC/bcr-abl vaccine. However, with the methods used, it was not possible to detect either a humoral or a cell-mediated immune response against SDF-1. Despite this, a number of notable effects of administering the pBSC/SDF-1 $\alpha$ plasmid were evident. These were associated with the oncogenic potential of bcr-abl-transformed 12B1 cells.

Administering the SDF- $1 \alpha$-expressing plasmid simultaneously with specific vaccination against these cells resulted in an increase in the survival among the vaccinated mice, although this difference was not significant. However, when only the development of solid tumors was considered, the results were different; the increased protection in doubly inoculated mice were significantly different.

A critical look at the present data suggests that this effect may be, at least in part, an 'artifact'. The increased leukemogenic potential that resulted in early leukemia onset in the SDF-1 $\alpha$-treated mice and the rapid death of the respective mice may have obscured the induction of solid tumors, which usually appears later than does fatal leukemia. Therefore, it is reasonable to assume that at least a number of the mice that died early of leukemia would have developed solid tumors later on. However, these results strongly suggest that SDF-1 $\alpha$ plasmid administration resulted in a significant enhancement of the leukemogenic potential of 12B1 cells.

The results obtained in the present study were associated with the nature of the cells used. The 12B1 cells are of pre-B origin, they express the BCR-ABL protein, produce substantial amounts of CXCR4 and also produce HIF-1 $\alpha$. This transcription factor is known to upregulate CXCR4 expression (27) and has been demonstrated to be required for the survival of leukemic stem cells in a mouse CML model (28). The role of the chemokine SDF-1 $\alpha$ in patients with leukemia has been most frequently discussed in association with the role of the SDF-1 $\alpha /$ CXCR4 axis during the pathogenic process (29). It has been assumed that SDF-1 $\alpha$ interactions with CXCR4 are crucial for leukemic stem cell adhesion to stromal cells, which would enable their self-renewal, proliferation and differentiation arrest. However, the current model is possibly more closely associated with the experimental diseases induced in NOD-SCID mice following administration of human acute leukemia cells (30) or T-leukemia cells (31). In these two studies, it was demonstrated that extramedullar niches had a significant role in the development of the experimentally induced disease. According to these authors, tumor cell replication was demonstrated in the neighborhood of bile ducts, with their subsequent accumulation in the portal area. When these liver-homed cells were exposed to SDF-1 $\alpha$ in vitro, the number of colonies that formed significantly increased. It is likely that in the present study, additional SDF- $1 \alpha$ formed following pBSC/SDF- $1 \alpha$ plasmid administration, contributed to the activities of these niches and possibly to the formation of other extramedullar niches, thereby facilitating the leukemogenic process. It has been suggested that in acute myeloid leukemia, SDF-1 has a role in the development of extramedullar disease (32).

In attempting to interpret the present data, the presence of the BCR-ABL protein in 12B1 cells must be taken into consideration. The results of the present study as evidence for its effect on SDF-1 $\alpha$ activity is controversial, and are inconsistent with the results of Salgia et al (33), which suggested that bcr-abl-transformed cell lines become refractory to SDF-1 $\alpha$. It has been repeatedly demonstrated that the BCR-ABL protein inhibits the chemotactic response to SDF-1 $\alpha$ (34-37). Several events have been implicated for these effects, including the downregulation of class II phosphoinositide 3-kinase (P13KC2 $\gamma$ ) (38), the increased expression of the $\beta 2$ integrin LFA-1 (37), activation of Cdc42 GTPase (39) and the activation of Lyn kinase (40). Tyrosine-kinase inhibitors, such as imatinib mesylate, reversed this phenomenon, which indicated a causal connection between the BCR-ABL protein and reduced CXCR4-associated activity. However, there have been other studies that, to a certain degree, question the role of the BCR-ABL protein in SDF $1 \alpha$-induced migration and homing of transformed cells, and that appear to be relevant to the present observations. According to one study, the effects of SDF-1 $\alpha$ on pseudopodia formation and migration from these niches were not suppressed by BCR-ABL activity (41). In fact, the authors observed increased pseudopodia formation and the transmigration of bcr-abl-transformed cells following their exposure to SDF-1 $\alpha$. It has also been demonstrated that SDF-1 $\alpha$, which inhibits the proliferation of primitive haematopoietic cells, failed to abrogate the proliferation of primitive human bcr-abl-positive cells (42). Another study reported that in bcr-abl-transformed cells, a reduced chemotactic response to SDF-1 $\alpha$ was paradoxically accompanied by increased spontaneous migration (35).

Based on these previously reported results, a tentative, simple mechanistic explanation of the present observations may be proposed. The SDF-1 $\alpha$ that was formed accelerated the migration of 12B1 cells to extramedullar niches where the proliferation of leukemic cells occurred that, in turn, was accelerated by the ability of this chemokine to support the growth of pre-B 12B1 cells. The rapid migration of these cells from the site of inoculation, if this truly occurred, reduced the number of cells that were capable of inducing subcutaneous tumors, thereby leading to a delay in their appearance or even to reducing the number of remaining cells below a tumor-inducing dose. These events may also be associated with the decreased adhesion of tumor cells to stromal cells, which would reduce the capability of $12 \mathrm{~B} 1$ cells to induce solid tumors. 
To be certain, this proposed explanation is subject to substantial corrections. In addition to the controversies already mentioned, other factors may be involved. For example, in addition to its chemotactic activity, SDF-1 $\alpha$ has multiple other functions, a number of which may act in concert to the phenomena observed. Furthermore, as suggested by Salanga et al (43), chemokines are not isolated entities, but act in complex networks with other signaling systems. In addition, it is impossible to neglect the expression of the BCR-ABL protein identified in the cells used in the present study. As previously noted, this protein is known to affect the functionality of the SDF-1 $\alpha / C X C R 4$ axis. It has also been demonstrated that a number of factors, including prostaglandin E, hyaluronic acid, fibrinogen, cleavage of the C3 component of complement, and others, prime or enhance the responsiveness of cells to SDF-1 $\alpha$ (44). To the best of our knowledge, their effect has not yet been adequately investigated.

All of the aspects outlined above make forming reliable conclusions from the present data particularly difficult. To establish extrapolations from the discrepant and frequently contrasting results of the previous studies on SDF-1 $\alpha$, which were performed using a wide spectrum of cell systems and were based on varying experimental designs, is not simple, and thus further studies are required to elucidate its role.

\section{Acknowledgements}

The authors are grateful to Miss Katerina Kernova and Miss Tereza Novakova for their excellent technical assistance. This study was supported by MZCR IGA NS 10634-3/2009, MZCR IGA NT 12363-4/2011, by grant ERDF OPPK CZ.2.16/3.1.00/24001, and by the project (Ministry of Health, Czech Republic) for Conceptual development of research organization (00023736 UHKT).

\section{References}

1. Raman D, Baugher PJ, Thu YM and Richmond A: Role of chemokines in tumor growth. Cancer Lett 256: 137-165, 2007.

2. Kryczek I, Wei S, Keller E, Liu R and Zou W: Stroma-derived factor (SDF-1/CXCL12) and human tumor pathogenesis. Am J Physiol Cell Physiol 292: C987-C995, 2007.

3. Nagasawa T, Kikutani $\mathrm{H}$ and Kishimoto T: Molecular cloning and structure of a pre-B-cell growth-stimulating factor. Proc Natl Acad Sci USA 91: 2305-2309, 1994.

4. Burger JA and Kipps TJ: CXCR4: a key receptor in the crosstalk between tumor cells and their microenvironment. Blood 107: 1761-1767, 2006.

5. Karin N: The multiple faces of CXCL12 (SDF-1alpha) in the regulation of immunity during health and disease. J Leukoc Biol 88: 463-473, 2010.

6. Duda DG, Kozin SV, Kirkpatrick ND, et al: CXCL12 (SDF1alpha)-CXCR4/CXCR7 pathway inhibition: an Emerging sensitizer for anticancer therapies? Clin Cancer Res 17 2074-2080, 2011.

7. Burns JM, Summers BC, Wang Y, et al: A novel chemokine receptor for SDF-1 and I-TAC involved in cell survival, cell adhesion, and tumor development. J Exp Med 203: 2201-2213, 2006.

8. Hattermann $\mathrm{K}$ and Mentlein R: An infernal trio: the chemokine CXCL12 and its receptors CXCR4 and CXCR7 in tumor biology. Ann Anat 195: 103-110, 2013.

9. Kucia M, Reca R, Miekus K, et al: Trafficking of normal stem cells and metastasis of cancer stem cells involve similar mechanisms: pivotal role of the SDF-1-CXCR4 axis. Stem Cells 23: 879-894, 2005.
10. Brzoska E, Kowalewska M, Markowska-Zagrajek A, et al: Sdf-1 (CXCL12) improves skeletal muscle regeneration via the mobilisation of CXCR4 and CD34 expressing cells. Biol Cell 104: 722-737, 2012.

11. Orimo A, Gupta PB, Sgroi DC, et al: Stromal fibroblasts present in invasive human breast carcinomas promote tumor growth and angiogenesis through elevated SDF-1/CXCL12 secretion. Cell 121: 335-348, 2005.

12. Wang J, Wang J, Dai J, et al: A glycolytic mechanism regulating an angiogenic switch in prostate cancer. Cancer Research 67: 149-159, 2007.

13. Cojoc M, Peitzsch C, Trautmann F, et al: Emerging targets in cancer management: role of the CXCL12/CXCR4 axis. Onco Targets Ther 6: 1347-1361, 2013.

14. Schimanski CC, Galle PR and Moehler M: Chemokine receptor CXCR4-prognostic factor for gastrointestinal tumors. World J Gastroenterol 14: 4721-4724, 2008.

15. Felix AS, Weissfeld J, Edwards R and Linkov F: Future directions in the field of endometrial cancer research: the need to investigate the tumor microenvironment. Eur J Gynaecol Oncol 31: 139-144, 2010.

16. Burger JA and Peled A: CXCR4 antagonists: targeting the microenvironment in leukemia and other cancers. Leukemia 23: 43-52, 2009.

17. Lee Ch, Kakinuma T, Wang J, et al: Sensitization of B16 tumor cells with a CXCR4 antagonist increases the efficacy of immunotherapy for established lung metastases. Mol Cancer Ther 5: 2592-2599, 2006.

18. McLaughlin J, Chianese $\mathrm{E}$ and Witte $\mathrm{ON}$ : In vitro transformation of immature hematopoietic cells by the P210 BCR/ABL oncogene product of the Philadelphia chromosome. Proc Natl Acad Sci USA 84: 6558-6562, 1987.

19. Lucansky V, Sobotkova E, Tachezy R, Duskova M and Vonka V: DNA vaccination against bcr-abl-positive cells in mice. Int J Oncol 35: 941-951, 2009.

20. Jelínek F1, Sobotková E and Vonka V: Characteristics of two mouse bcr-abl-transformed cell lines. II. Pathological lesions induced in mice. Folia Biol (Praha) 51: 93-102, 2005.

21. Sobotkova E1, Ludvíková V, Petrácková M, et al: Characteristic of two mouse bcr-abl-transformed cell lines: I. General properties of the cells. Folia Biol (Praha) 51: 12-18, 2005.

22. Jinoch $\mathrm{P}$, Zak R, Janousková $\mathrm{O}$, et al: Immunization with live HPV-16-transformed mouse cells expressing the herpes simplex thymidine kinase and either GM-CSF or IL-2. Int J Oncol 23: 775-783, 2003.

23. Ludvíková V1, Hamsíková E, Sobotková E, et al: Use of polyclonal rabbit antibodies for detection of the bcr-abl fusion zone in cells transfected with experimental bcr-abl DNA vaccines. Int J Oncol 27: 265-274, 2005.

24. Smahel M, Síma P, Ludvíková V and Vonka V: Modified HPV16 E7 genes as DNA vaccine against E7-containing oncogenic Cells. Virology 281: 231-238, 2001.

25. Hrbacek J, Urban M, Hamsikova E, et al: Serum antibodies against genitourinary infectious agents in prostate cancer and benign prostate hyperplasia patients: a case-control study. BMC Cancer 11: 53, 2011.

26. Poláková I1, Pokorná D, Dusková M and Smahel M: DNA vaccine against human papillomavirus type 16: modifications of the E6 oncogene. Vaccine 28: 1506-1513, 2010.

27. Cronin P, Wang J and Redmond HP: Hypoxia increases the metastatic ability of breast cancer cells via upregulation of CXCR4. BMC Cancer 10: 225, 2010.

28. Zhang H, Li H, Xi HS and Li S: HIFl $\alpha$ is required for survival maintenance of chronic myeloid leukemia stem cells. Blood 119: 2595-2607, 2012.

29. Kittang AO, Hatfield K, Sand K, Reikvam H and Bruserud Ø: The chemokine network in acute myelogenous leukemia: molecular mechanisms involved in leukemogenesis and therapeutic implications. Curr Top Microbiol Immunol 341: 149-172, 2010.

30. Kato I, Niwa A, Heike T, et al: Identification of hepatic niche harboring human acute lymphoblastic leukemic cells via the SDF-1/CXCR4 axis. PLoS One 6: e27042, 2011.

31. Kawaguchi A, Orba Y, Kimura T, et al: Inhibition of the SDF-1alpha-CXCR4 axis by the CXCR4 antagonist AMD3100 suppresses the migration of cultured cells from ATL patients and murine lymphoblastoid cells from HTLV-I Tax transgenic mice. Blood 114: 2961-2968, 2009.

32. Sison EA and Brown P: The bone marrow microenvironment and leukemia: biology and therapeutic targeting. Expert Rev Hematol 4: 271-283, 2011. 
33. Salgia R, Quackenbush E, Lin J, et al: The BCR/ABL oncogene alters the chemotactic response to stromal-derived factor-1alpha. Blood 94: 4233-4246, 1999.

34. Dürig J, Rosenthal C, Elmaagacli A, et al: Biological effects of stroma-derived factor- 1 alpha on normal and CML CD $34^{+}$haemopoietic cells. Leukemia 14: 1652-1660, 2000.

35. Ptasznik A, Urbanowska E, Chinta S, et al: Crosstalk between $\mathrm{BCR} / \mathrm{ABL}$ oncoprotein and CXCR4 signaling through a Src family kinase in human leukemia cells. J Exp Med 196: 667-678, 2002.

36. Geay JF, Buet D, Zhang Y, et al: p210BCR-ABL inhibits SDF-1 chemotactic response via alteration of CXCR4 signaling and down-regulation of CXCR4 expression. Cancer Res 65: 2676-2683, 2005.

37. Chen YY, Malik M, Tomkowicz BE, Collman RG and Ptasznik A BCR-ABL1 alters SDF-1alpha-mediated adhesive responses through the beta2 integrin LFA-1 in leukemia cells. Blood 111: $5182-5186,2008$

38. Yu W, Sun X, Tang H, Tao Y and Dai Z: Inhibition of class II phosphoinositide 3-kinase gamma expression by p185(Bcr-Abl) contributes to impaired chemotaxis and aberrant homing of leukemic cells. Leuk Lymphoma 51: 1098-1107, 2010.
39. Chang YC, Tien SC, Tien HF, et al: p210Bcr-Abl desensitizes Cdc42 GTPase signaling for SDF-1alpha-directed migration in chronic myeloid leukemia cells. Oncogene 28: 4105-4115, 2009.

40. Tabe Y, Jin L, Iwabuchi K, et al: Role of stromal microenvironment in nonpharmacological resistance of CML to imatinib through Lyn/CXCR4 interactions in lipid rafts. Leukemia 26: 883-892, 2012

41. Fruehauf S, Srbic K, Seggewiss R, Topaly J and Ho AD Functional characterization of podia formation in normal and malignant hematopoietic cells. J Leukoc Biol 71: 425-432, 2002.

42. Cashman J, Clark-Lewis I, Eaves A and Eaves C: Stromal-derived factor 1 inhibits the cycling of very primitive human hematopoietic cells in vitro and in NOD/SCID mice. Blood 99: 792-799, 2002.

43. Salanga CL, O'Hayre M and Handel T: Modulation of chemokine receptor activity through dimerization and crosstalk. Cell Mol Life Sci 66: 1370-1386, 2009.

44. Ratajczak MZ, Serwin K and Schneider G: Innate immunity derived factors as external modulators of the CXCL12-CXCR4 axis and their role in stem cell homing and mobilization. Theranostics 3: 3-10, 2013. 